\title{
Situating the "Research Paper" Assignment in the IT Workplace
}

\author{
Arthur B. Kahn \\ University of Baltimore, Baltimore, MD, USA
}

ArthurKahn@ComCast.Net

Abstract

The "Research Paper" is a classic assignment in many IT courses. We explore its pedagogical advantages and weaknesses, especially since most students have career goals in the workplace rather than in academia. It is proposed that the research paper assignment be reformulated as a rhetorical case. This is a case-teaching device which is similar to, but distinct from the business case. We conclude by conceptualizing a simulated internship which can re-situate a broad range of IT "Research Papers" into the workplace.

This work received support from the Mary and William G. Baker Faculty Fellowship.

\section{Introduction}

The "Research Paper" (RP) is a classic assignment in many Information Technology (IT) courses. When properly executed, it develops critical analysis and exercises many supporting skills. Students learn how to search the literature and how to evaluate the quality and the relevance of their "hits." They learn how to extract pertinent material, and how to summarize, paraphrase or quote it. They learn how to reorganize the material, write smooth transitions and synthesize it into a coherent whole. They learn how to cite and document their sources.

The RP goes beyond exercising research and writing skills. While searching the IT literature, students see how IT experts apply principles in practice. The students become acquainted with established experts, what they have to say, and how they say it. The RP (Research Paper) introduces students to the lore and style of the IT community of discourse.

Despite these advantages, there is a downside to the RP. First, there is a question of relevance. The RP is an important genre in the workplace of academia û professors must publish or perish. But only a tiny minority of undergraduate IT students aspire to professorial positions. Most IT students seek careers as practitioners in the IT workplace. Many perceive the RP as having little relevance to their career aspirations.

Even for those who aim for academic careers, the RP is rhetorically problematic. Since Aristotle, rhetoric has been concerned with the interplay between the writer's role, his audience and his purpose. The real

Material published as part of these proceedings, either on-line or in print, is copyrighted by Informing Science. Permission to make digital or paper copy of part or all of these works for personal or classroom use is granted without fee provided that the copies are not made or distributed for profit or commercial advantage AND that copies 1) bear this notice in full and 2) give the full citation on the first page. It is permissible to abstract these works so long as credit is given. To copy in all other cases or to republish or to post on a server or to redistribute to lists requires specific permission from the publisher at publister@intormingscience.org world Research Paper is written by experts to convince an audience of fellow experts that the author has discovered new insight which is valid and valuable. Unfortunately, most undergraduates are not ready for original research. Thus the RP becomes a survey of secondary literature. This is further compounded because the student is a novice writing to an expert teacher. The mind set of the student writing an RP frequently degenerates into, 
"My role, as author, is a student. My audience is the teacher. And my purpose is to prove my knowledge of the material, or at least that I have read the book."

This classroom psyche is reinforced by RP after RP in course after course through year after year in our educational system. It is little wonder that it proves difficult for graduates to transfer writing skills from the classroom to the workplace. The student must move from, "Show the teacher all that I know " to "Tell the clients what they need to know." (Source unknown)

This paper proposes to re-frame the RP as a Rhetorical Case, to better facilitate the transfer of writing skills from classroom to workplace. Furthermore, we will retain the advantages of the RP and eliminate many of its difficulties. We proceed by comparing the Rhetorical Case with the Business Case which is more familiar to IT faculty. Then we shall introduce WRITE Inc., a hypothetical consulting firm, which provides a simulated internship in which our students can pursue a wide range of research/writing assignments for IT clients.

\section{Rhetorical Case}

The Rhetorical Case, like the Business Case, is a case teaching vehicle. But the two are distinct. Both types of cases establish a rich scenario involving a workplace organization. The Business Case usually involves complex decision-making. Although it may require written analysis of the decision, it rarely involves writing within the workplace context. The Rhetorical Case is the natural sequel to the Business Case. It deals with dissemination of the made-decision. A key characteristic of the Rhetorical Case is that it always requires the student to assume a role within the case scenario and to write for a workplace audience.

For example, a business case could involve the recent Excite.com bankruptcy. Many ISPs such as @home and @ verio, which leased backbone lines from Excite, had to very quickly cope with many technical and strategic issues. Should we switch to another network? Should we develop our own? Should we get out of this business? If we develop our own network, should it be dial-up, cable or digital?

In a Business Case, students are immersed into the role of consultants who must consider the alternatives. They must balance many factors: contractual obligations, customer goodwill, franchises agreements, cost efficiency, development time, capital investment, as well as competition. Once the consultants reach a decision the business case is completed. (ComCast decided to develop their own network, and Verio exited from the ISP business.) Harvard Business Cases, other published business cases, and even minicases in text books, may include discussion questions intended to prime class deliberations. But they leave the rhetorical triad unspecified and do not require writing situated in the workplace.

Sometimes the instructor will request a "Case Analysis." However, again, this is intended to stimulate class discussion. Case analysis is a genre for the business class rather than for business. At best, it is implied that the student is in the role of a consultant addressing fellow consultants (classmates) for the purpose of convincing them that her interpretation of the case is valid and has value. The Case Analysis genre is comparable to a theater critic's review. It is about, rather than within the drama.

A Rhetorical Case moves the writer from an observer-critic to an actor participant. It asks the student to assume a role within the action. A rhetorical case starts with the made-decision and deals with its propagation to an appropriate audience. The business case, which ends with a decision to close a plant, may segue into many alternative rhetorical cases. A student may be asked to assume the role of the Director of Personnel notifying the union of the impending closing; or, the Marketing Manager assuring customers that their service will be unaffected; or, the Chief Financial Officer telling financial advisors how the plant closing will improve the return on investment. A Rhetorical Case always requires the student to assume the role of a character in the scenario and in this role address a rhetorical challenge posed by the case. 
Kahn

\begin{tabular}{|c|c|}
\hline \multicolumn{2}{|c|}{ CASE TEACHING } \\
\hline Business Case & Rhetorical Case \\
\hline Make a Decision & $\begin{array}{l}\text { Disseminate the } \\
\text { Made-Decision }\end{array}$ \\
\hline $\begin{array}{l}\text { Situated Writing } \\
\text { Rarely Required }\end{array}$ & $\begin{array}{l}\text { Situated Writing } \\
\text { Always Required }\end{array}$ \\
\hline $\begin{array}{c}\text { Rhetorical Triad } \\
\text { Haphazard }\end{array}$ & $\begin{array}{c}\text { Always includes Triad: } \\
\text { Writer's Role } \\
\text { Purpose } \\
\text { Audience }\end{array}$ \\
\hline $\begin{array}{c}\text { Case Analysis } \\
\text { Genre }\end{array}$ & $\begin{array}{c}\text { Any Business } \\
\text { Genre }\end{array}$ \\
\hline Critic - Observer & Actor - Participant \\
\hline Writing-to-Learn & Learning-to-Write \\
\hline & \\
\hline
\end{tabular}

Table 1. Distinctions between the business case and the rhetorical case

Since Informing Sciences cuts across disciplines, we should include in our comparison the viewpoint of WAC (Writing Across the Curriculum). Rhetorical cases tend to focus on learning-to-write. However, writing assignments attached to business cases tend to emphasize writing-to-learn. Mini cases in text books, or adapted by business faculty tend to be littered with teacher hints on which principles to apply and in what sequence (Kahn \& Stevens, 1998). The distinctions between the business case and the 
rhetorical case are shown in Table 1. Both are case-teaching vehicles, but they differ in purpose, and design. Although, it is possible to link a rhetorical case to a business case, it is not trivial matter to attain a seamless weld.

Rhetorical cases are frequently used in Business Communications and in Technical Writing courses. Text books in both fields usually have mini cases at the end of each chapter. Case books are also available (Weeks \& Locker, 1978.) An early discussion of rhetorical cases is Weeks and Fields (1978). There is also a collection of papers on various aspects of the rhetorical case edited by Brockmann (1984a) which includes papers by Couture \& Rymer as well as Green.

\section{Rhetorical Dissonance}

It appears that business faculty intuitively strive to develop rhetorical cases. Kahn and Stevens (1998) examined 49 writing assignments in business courses and found that 27 attempted to situate the writing in the workplace. Unfortunately 26 of the 27 exhibited various forms of rhetorical dissonance.

Kahn [1999] discusses rhetorical dissonance. He found many writing assignments in business content courses in which the suspense of belief, the student's illusion that he is playing a professional role, is shattered by intrusion of the teacher's voice. A clear cut example occurs in this succinct assignment from an economics course.

You are an economic advisor to the President of the United States. He has asked for your recommendation on how to allocate a $\$ 2$ billion surplus. Do not forget to use the spell checker and set one inch margins.

The first two sentences immerse the student in a powerful role within the White House. If appropriate class discussion prepares students, they become psyched to play the role. But the last sentence punctures the illusion that they are in a White House office. Spell checkers and one inch margins are not presidential. Intrusion of the teacher's voice reminds them that they are students writing to the teacher to get a grade.

Kahn (1999) defines rhetorical dissonance as a characteristic of a poorly designed rhetorical case. It is not a real life phenomenon. Rhetorical Dissonance occurs solely because of omissions or inconsistencies in a simulation of the WorkPlace within the classroom. Omissions neglect some or all elements of the rhetoric triad. Inconsistencies arise when pedagogical cues are allowed to intrude upon the WorkPlace setting.

Kahn and Stevens (1998) found many forms of such intrusion. Frequently, the assignment includes teacher hints for a sequence of problem solving steps based on principles explored in the chapter.

Sometimes the genre required is inappropriate, e.g., an academic paper where a business letter was more appropriate. In other cases the required content is inappropriate, e.g., a tutorial on a basic principle addressed to an expert. Finally, there are errors of omission. The assignment omits one or more elements of Aristotle's triad: a writer's role, an audience, and a purpose. Regardless of motive, rhetorical dissonance occurs. The student reaction to rhetorical dissonance is much like the instinctive reaction of a startled turtle. The students withdraw into the protective shell of familiar classroom writing, "I am a student, writing to a teacher to prove knowledge, or at least, effort."

\section{Recapitulation}

The Research Paper Assignment reinforces many critical analysis skills. It also introduces the student to the IT body of literature. But, it is not overly relevant to most of our students, who aspire to careers as IT practitioners. Perhaps this motivates many business faculty to attempt development of workplace-situated writing assignments. Unfortunately, most of these attempts fall into the trap of rhetorical dissonance. One probable reason is that many of the attempts appear to be business cases with a writing assignment 
Kahn

crudely appended. We need more sophisticated methods to re-formulate the Research Paper as a Rhetorical Case within a scenario which is more relevant to IT students.

\section{Rhetorical Case Literature}

We start with a brief review of pertinent literature. Bitzer (1963) indicated that there must be an exigency, a real world need to change the audience's state of knowledge, belief or action. Several authors discuss challenges in the construction of a Rhetorical Case in a collection of papers edited by Brockmann (1984a). In his own paper, Brockmann (1984b) states that a rhetorical case must be embedded in a rich similitude of a workplace organization. The case must describe all relevant aspects of an organization, its internal structure and culture as well as its environment: customers, suppliers, competitors, and regulators. The scenario must also include a role for the writer, and an audience. And finally, there must be a need to write in order to fulfill some organizational purpose. Kahn (1999) provides a step-by-step guide for developing a rhetorical case for a content course. However, development from scratch can be burdensome. It would be easier to construct a rhetorical Case on the foundation of a pre-built shell.

\section{WRITE Inc.}

Such a base is provided by a hypothetical consulting firm, WRITE Inc. (Writers / Researchers in the IT Environment). This firm researches any IT issue for diverse clients: IT firms, IT users, government agencies on any level, and diverse special issue groups such as the ACLU, the NAACP and the NRA.

Students are immersed in a simulated internship at WRITE Inc. following the pattern established by Kahn (1995). As shown in Table 2, the classroom morphs into the workplace of WRITE Inc. Students become intern writer/researchers. The supervisor is no longer a teacher, but a manager/mentor. A workplace audience is substituted for the teacher. Finally, the purpose shifts from earning a grade to advancing the client toward her goal. The goal is no longer to prove knowledge, but to provide knowledge.

\begin{tabular}{|c|c|c|c|}
\hline \multicolumn{2}{|c|}{ Aspect $\backslash$ Venue } & IT Class & WRITE Inc \\
\hline \multicolumn{2}{|c|}{ Environment } & Classroom & Workplace \\
\hline \multicolumn{2}{|c|}{ Supervisor } & Teacher & Manager / Mentor \\
\hline \multirow{3}{*}{$\begin{array}{c}\mathrm{T} \\
\mathrm{R} \\
\mathrm{I}\end{array}$} & Writer Role & Student & Writer/Researcher \\
\hline & & & \\
\hline & Audience & Teacher-Audience & Work place audience \\
\hline \multirow{2}{*}{$\begin{array}{l}A \\
D\end{array}$} & \multirow{2}{*}{ Purpose } & Earn Grade & Advance Client's Goal \\
\hline & & Prove knowledge & Provide Knowledge \\
\hline
\end{tabular}

Table 2. Conversion of ClassRoom to WorkPlace

WRITE Inc. has endless potential for clients and issues. A small company may not have an internal research/writing group. A large company may seek a fresh view, perhaps resolution of some internal conflict. A case may involve technical issues. Its scope may be limited to evaluation of vendor proposals 
for a new internal Information System. The issue could be as far reaching as an industry-wide standard for some new product such as HDTV. The questions could be straightforward. Or, the decisions could involve complex combinations of technical, legal and ethical concerns, as in the Microsoft case, the Toysmart case, and the Napster case. WRITE Inc. provides a workplace infrastructure which can support most genres used for writing projects in IT courses: survey papers, strategic or technical recommendations, and even the Research Paper.

WRITE Inc. is focused on serving clients. Therefore, matters like project deadlines are driven by commitments to clients and their needs, not classroom housekeeping. The firm's primary products are written documents. Therefore it is plausible that WRITE Inc. might have a style manual which covers pertinent mechanic such as 1" margins and use of a spell checker. It is not in character for the President of the United States, or for many other clients to deal with such matters. But a Style Manual is an important guide within a company like WRITE Inc. Prototypes for such consulting firms can easily be found by searching the net with keywords: "Information Technology," "research," "writer," and "White Paper."

This scenario provides the essential infrastructure and a general framework which are missing in the failed attempts to extend a business case into a rhetorical case found by Kahn and Stevens (1998). The client engagement encapsulates the traditional business case used in IT courses. This should make it much easier for IT faculty who wish to develop a rhetorical case.

\section{Conclusion}

Although I taught IT courses for many years, in my retirement I have chosen, for a change of pace, to teach advanced composition in the English Department. WRITE Inc. is an adaptation of a writing assignment I developed to substitute for the obligatory "Research Paper" in the service course in advanced composition. In that context, the consulting firm is PRO, Inc. (Policy Research Organization.)

The original assignment was based upon events which have taken place in Buffalo NY since 1992. The abortion issue had escalated in serious violence each summer. Finally, a local group sought to create an atmosphere of civility and respect. They organized a local council which included representatives of all viewpoints. Their efforts proved successful and led to a network local of groups loosely affiliated with a national organization, Common Ground. The students in my writing class became interns at PRO, Inc. with the Common Ground Council of Buffalo as their hypothetical client. Their mission was to write a balanced survey of positions û a review which fairly presented all viewpoints. To assist in setting an objective tone, all statements must be backed by authoritative documentation. During progress of the assignment, the interns would pair off and search each other's papers for bias. Ultimately this assignment included all the skills exercised by the Research Paper. But it generated considerably more interest, even excitement.

In subsequent semesters, I urged the interns to find their own clients and issues and submit proposals. The basic requirements are that the issue must be currently debatable, but mature enough for an authoritative literature to exist. A sample of the topics includes: the death penalty, euthanasia, health insurance, abortion, and gun control, as well as internet issues include privacy, security and pornography.

The interns find that it is very challenging, to write a paper with absolutely no slant. They come to the conclusion that it is impossible. However, the exercise gives them aa greater sensitivity and hopeful better control over bias. Frequently, I use a follow on assignment in which they are engaged by one of the stakeholders to write a paper propounding their viewpoint. The juxtaposition of these two engagements provides insights into the difference between two important genres.

The Research Paper develops a variety of investigative and analytical skills. Furthermore, it acquaints the student with the authoritative literature as well as the authorities of the IT disciplines. However, a 
Kahn

rhetorical case can accomplish all of these objectives, and provide greater relevance to the practitioner career, which most students seek. This has been demonstrated in a composition course. The advantages of a simulated IT internship have also been demonstrated in a systems analysis course. It remains to test WRITE Inc. scenarios in IT courses. I encourage such an effort, and I offer my assistance.

\section{References}

Bitzer, L.F. (1963): The Rhetorical Situation. Philosophy and Rhetoric. 1, 1-14.

Brockmann, R.. John (Ed.) (1984a): The Case Method in Technical Communication: Theory and Models. Association of Teachers of Technical Writing (ATTW). 201 pages.

Brockmann, R. John (1984b): What is a Case? In: The Case Method in Technical Communication: Theory and Models. (Ed: Brockmann,John R) ATTW. 1-16.

Couture, Barbara; Rymer, Jone (1984): Cases as Communication Problems for Writers: How Do They Differ? In: The Case Method in Technical Communication: Theory and Models. (Ed: Brockmann, John R.) ATTW, 25 - 32.

Green, M.M. (1984): How to Use The Case Method. In: The Case Method in Technical Communication. (Eds: Brockmann, John R., et al.) The Association of Teachers of Technical Writing.

Kahn, Arthur B. (1995): Simulated Apprenticeship in Systems Analysis Courses. J. Comp. Info. Sys. Ed. 35 /2, 5 - 15.

Kahn, Arthur B., Stevens, Ralph (1998): Writing Assignments in the Business Curriculum. CCCC.

Kahn, Arthur B. (1999) Design of Effective Writing Assignments û Rhetorical Cases vs. Business Cases. Proceedings SE INFORMS 35

Weeks, Francis W. 1978): How to Write Problems. In: The Teaching of Business Communication. (Ed: Douglas, D.H.) American Business Communications Association, Champaign, Illinois, 223 - 229.

Weeks, Francis W. Locker, Kitty O. (1980): Business Writing Cases and Problems. Stipes, Champaign IL.

\section{Biography}

President Clinton once stated that the average American during his work years will have six changes of careers, not jobs. Art Kahn has done his share toward making an honest man of Bill Clinton.

While earning a PhD at Johns Hopkins University in Meteorology, Art used early computers to support his research and became absorbed in computer applications. He worked for ten years as a computer applications analyst at Westinghouse Defense Center in Baltimore providing support for design of electronic weapons and space systems. Following a Visiting professorship in Computer Science at the University of Wisconsin Madison, Art returned to Westinghouse as an Information Systems Analyst. A major responsibility was teaching engineers and managers how to make effective use of computers. After saturating the market for computer education at Westinghouse, he moved to the University of Baltimore as a professor in Information Systems.

He became involved in WAC as a content teacher. He completed the Maryland Writing Project Summer Teachers Institute in 1994 and began teaching advanced composition in the English department. His continuing interest is ways and means to develop Rhetorical Cases with writing assignments embedded in a WorkPlace scenario. 